\title{
Detection of cytokine storm in patients with achalasia using ELISA
}

\author{
TSUTOMU KANDA $^{1 *}$, AKIRA YOSHIDA $^{1 *}$, KUMI OGIHARA $^{2}$, HITOMI MINAMI $^{2}$, NAOYUKI YAMAGUCHI ${ }^{2}$, \\ YUICHIRO IKEBUCHI ${ }^{1}$, KAZUHIKO NAKAO ${ }^{2}$ and HAJIME ISOMOTO ${ }^{1}$
}

${ }^{1}$ Division of Gastroenterology and Nephrology, Faculty of Medicine, Tottori University, Yonago, Tottori 683-8504;
${ }^{2}$ Department of Gastroenterology and Hepatology, Nagasaki University, Nagasaki 852-8501, Japan

Received February 1, 2021; Accepted May 19, 2021

DOI: $10.3892 / b r .2021 .1438$

\begin{abstract}
Esophageal achalasia is characterized by abnormal peristaltic movements of the esophageal body and impaired relaxation of the lower esophageal sphincter (LES). However, its etiology remains unknown. In our previous study, it was shown that in the LES of patients with achalasia, hsv1-miR-H1 was overexpressed, ATG16L1 expression was downregulated and interleukin (IL)-1 $\beta$ levels were upregulated. However, systemic features were not evaluated. Herein, the plasma cytokine levels in patients with achalasia were determined. Plasma was collected from patients at Nagasaki University Hospital between February 2013 and March 2016, both before and after peroral endoscopic myotomy (POEM). Cytokine analysis was performed using plasma collected from 10 healthy individuals (control group) and 12 patients with achalasia using the Bio-Plex Pro ${ }^{\mathrm{TM}}$ Human Cytokine 27-plex assay kit. The levels of IL-17, IL-1 $\beta$, C-C motif chemokine ligand 2, IL-4, IL-5, IL-1ra, IL-7, IL-12, interferon- $\gamma$, IL-2, fibroblast growth factor-2, colony-stimulating factor (CSF) 2 and CSF3 were significantly higher in patients with achalasia compared with the control subjects. However, the levels did not differ between plasma samples collected before and after POEM. Thus, the occurrence of a cytokine storm was confirmed in the patients with achalasia.
\end{abstract}

\section{Introduction}

Esophageal achalasia, a typical esophageal dyskinesia, is characterized by impaired relaxation of the lower esophageal sphincter (LES), as well as abnormal peristaltic movements

Correspondence to: Dr Tsutomu Kanda, Division of Gastroenterology and Nephrology, Faculty of Medicine, Tottori University, 36-1 Nishi-cho, Yonago, Tottori 683-8504, Japan

E-mail: tsutomu-k@tottori-u.ac.jp

\section{*Contributed equally}

Abbreviations: CSF, colony-stimulating factor; FGF-2, fibroblast growth factor-2; HSV, herpes simplex virus; LES, lower esophageal sphincter; NK, natural killer; PMN, polymorphonuclear leukocyte; POEM, peroral endoscopic; myotomy; Th, T helper

Key words: achalasia, peroral endoscopic myotomy, cytokine storm of the esophageal body. Esophageal achalasia can impair the ability to digest food and thus reduce a patient's quality of life. Human herpes virus 1 encoded microRNAs have been identified in biopsy samples of the LES muscle during peroral endoscopic myotomy (POEM) for esophageal achalasia (1-3). The disease was first reported $\sim 300$ years ago, but its underlying cause remains unknown (4). Current treatment strategies employ various methods, including endoscopic balloon dilatation, botulinum toxin injection, laparoscopic Heller myotomy, and surgical resection of the affected esophagus in advanced and severe cases (5). Recently, POEM has been established as a minimally invasive method for treating achalasia (6). This treatment is effective and safe, even in elderly patients, and exhibits favorable short- and long-term prognoses $(6,7)$. Sato et al (8) performed peroral endoscopic biopsies of the muscular layer termed POEM-b, with histopathological and immunohistochemical analysis of POEM-b samples showing signs of neurodegeneration rather than inflammatory infiltration into the muscle layer (8). Based on the Chicago classification criteria $(9,10)$, high-resolution manometry revealed that patients with type III achalasia tended to exhibit preserved interstitial cells of Cajal, whereas patients with type I achalasia were more likely to present with more severe fibrosis $(8,11)$.

The proposed causative factors for achalasia are diverse and multifactorial, with complex interactions between autoimmune and inflammatory responses that can be initiated by viral infections in genetically susceptible patients (2). One causative agent includes the herpes simplex virus (HSV), a neurotrophic virus that predominates in squamous epithelium, varicella-zoster virus, measles virus and human papillomavirus $(4,5,7,12)$. In addition, HSV type 1 (HSV 1) DNA and RNA have been detected in the tissues of all patients with achalasia, but not in the tissues of control subjects (13). Therefore, HSV 1 infection may be significantly associated with the development and/or progression of achalasia.

In our previous study, it was shown that the viral agents hsv1-miR-H1 and hsv1-miR-H18, which are neurotropic HSV-1-derived biomolecules, were overexpressed in the LES muscle of Japanese achalasia cohorts (1). Furthermore, ATG16L1 expression was lower, whereas interleukin (IL)-1 $\beta$ expression was higher in the LES of patients with achalasia compared with that of the control subjects. Therefore, ATG16L1 may be targeted by hsv1-miR-H1, and the downregulation of ATG16L1 may be related to the inflammatory response (14). 
However, these data were collected from studies conducted on LES tissues and not from the plasma of patients with achalasia. Similarly, tissue cytokine analysis reports for patients with achalasia are available. IL-17 is produced by 17 subsets of T helper (Th) and is an essential mediator of autoinflammatory diseases. The frequency of IL-17A-secreting cells in the intestinal plexus of peripheral cells and esophageal tissue is reportedly higher in patients with achalasia compared with the control subjects $(5,13)$. IL-4 is an anti-inflammatory cytokine synthesized primarily by Th2 cells and it inhibits the synthesis of IL-1 $\beta$, tumor necrosis factor (TNF)- $\alpha$, IL-6 and IL-17. Moreover, patients with achalasia have a significantly higher proportion of circulating and tissue IL- $4^{+}$cells compared with the control subjects $(5,13)$. IL-13 has exhibits similar functions to that of IL-4, as well as regulating the type I collagen gene, and it is therefore involved in fibrosis. Its expression pattern in patients with achalasia is similar to that of IL-4 $(5,13)$. Furthermore, interferon (IFN)- $\gamma$ released from Th1 cells is essential for regulating immune responses. Patients with achalasia have a significantly higher proportion of circulating and tissue IFN- $\gamma^{+} / \mathrm{CD} 4^{+} \mathrm{T}$ cells compared with the control subjects $(5,13)$.

Cytokine storms are reportedly associated with a variety of infectious and non-infectious diseases. COVID-19, which is caused by SARS-CoV-2, is a potentially deadly disease that has sparked a global pandemic. Blood cytokine and chemokine levels are significantly higher in patients with COVID-19, including IL-1 $\beta$, IL-1ra,IL-7, IL-8, IL-9, IL-10, fibroblast growth factor-2 (FGF2), colony-stimulating factor (CSF)3 [a granulocyte-macrophage colony-stimulating factor (GM-CSF)], CSF2 (a GM-CSF), IFN- $\gamma$, CXCL10 (IP-10), chemokine (C-C motif) ligand 2 [CCL2 or monocyte chemoattractant protein 1 (MCP1)], CCL3 (also known as MIP1 $\alpha$ ), CCL4 (also known as MIP1 $\beta$ ), platelet-derived growth factor (PDGF)-BB, TNF- $\alpha$ and vascular endothelial factor (VEGF) (15-17). Some severe cases admitted to the intensive care unit exhibited high levels of inflammatory cytokines, including IL-2, IL-7, IL-10, CSF3, CXCL10, CCL2, CCL3 and TNF- $\alpha$ (15-17). However, the concept of cytokine storms, as well as the biological effects of cytokine overproduction, remain poorly defined.

As mentioned above, cytokines may be involved in the inflammatory response. However, there are few reports on plasma cytokine levels in patients with achalasia. In the present study, the cytokine levels in the plasma of patients with achalasia before and after POEM were measured, and compared with the values in healthy control subjects.

\section{Materials and methods}

Ethical considerations. Written informed consent was obtained from all the patients. The research protocol was approved by the Nagasaki University Ethics Committee (approval no. 13012899) under the ethical guidelines of the Declaration of Helsinki.

Peroral endoscopic muscular biopsy sampling during POEM. The standard POEM procedure was performed as previously described (6). Briefly, the following steps were followed: Submucosal injection and incision, submucosal tunneling, selective myotomy of the medial circular muscle and
Table I. Clinical characteristics of the 12 patients with achalasia.

\begin{tabular}{|c|c|}
\hline Characteristics & $\mathrm{n}$ \\
\hline Age, years, median (range) & $57(28-85)$ \\
\hline \multicolumn{2}{|l|}{$\operatorname{Sex}, \mathrm{n}(\%)$} \\
\hline Male & $4(33.3)$ \\
\hline Female & $8(66.7)$ \\
\hline Smoking, n (\%) & $3(25)$ \\
\hline \multicolumn{2}{|l|}{ Grade, n (\%) } \\
\hline 1 & $4(33.3)$ \\
\hline 2 & $7(58.3)$ \\
\hline 3 & $1(8.3)$ \\
\hline \multicolumn{2}{|l|}{ Type, n (\%) } \\
\hline Straight & $6(50)$ \\
\hline Sigmoid & $6(50)$ \\
\hline $\begin{array}{l}\text { Days after peroral endoscopic; myotomy, } \\
\text { median (range) }\end{array}$ & $97(83-104)$ \\
\hline Endoscopic balloon dilatation, n (\%) & $5(41.7)$ \\
\hline Body mass index, median (range) & $20(17-25)$ \\
\hline Eckardt score, median (range) & $9(4-10)$ \\
\hline \multicolumn{2}{|l|}{ Comorbidities, n (\%) } \\
\hline Diabetes & $1(8.3)$ \\
\hline High blood pressure & $3(25)$ \\
\hline Hyperuricemia & $1(8.3)$ \\
\hline Down syndrome & $1(8.3)$ \\
\hline Psoriasis vulgaris & $1(8.3)$ \\
\hline Pneumonia & $1(8.3)$ \\
\hline White blood cell, median (range) & $\begin{array}{c}5,100 \\
(3,600-11,300)\end{array}$ \\
\hline C-reactive protein, mg/dl, mean (range) & $\begin{array}{c}0.045 \\
(0.01-6.67)\end{array}$ \\
\hline
\end{tabular}

subsequent closure of the mucosal entrance. All patients who underwent POEM underwent endotracheal intubation with general anesthesia and positive pressure ventilation, including those who underwent surgery at Nagasaki University Hospital between February 2013 and March 2014. Patients with any severe underlying illnesses, such as cancer, patients who had undergone previous surgical treatment and those who could not tolerate general anesthesia were excluded. Patients were diagnosed with sporadic and classical achalasia by routine analysis, including barium follow-through and upper gastrointestinal endoscopy. Serum was collected on the day of or the day before POEM, as well as 290 days after POEM (Table I). All samples, including the control, were collected between February 2013 and March 2016 at Nagasaki University Hospital. Plasma was stored at $-20^{\circ} \mathrm{C}$ until required. Cytokine analysis was performed on plasma collected from 10 healthy volunteers as controls ( 5 men and 5 women; age range, 37-54 years; median age, 44 years) and 12 patients with achalasia ( 4 men and 8 women, including 3 smokers; age range, 28-85 years; median age, 57 years). According to descriptive rules for achalasia of the esophagus (18), 4 patients presented 

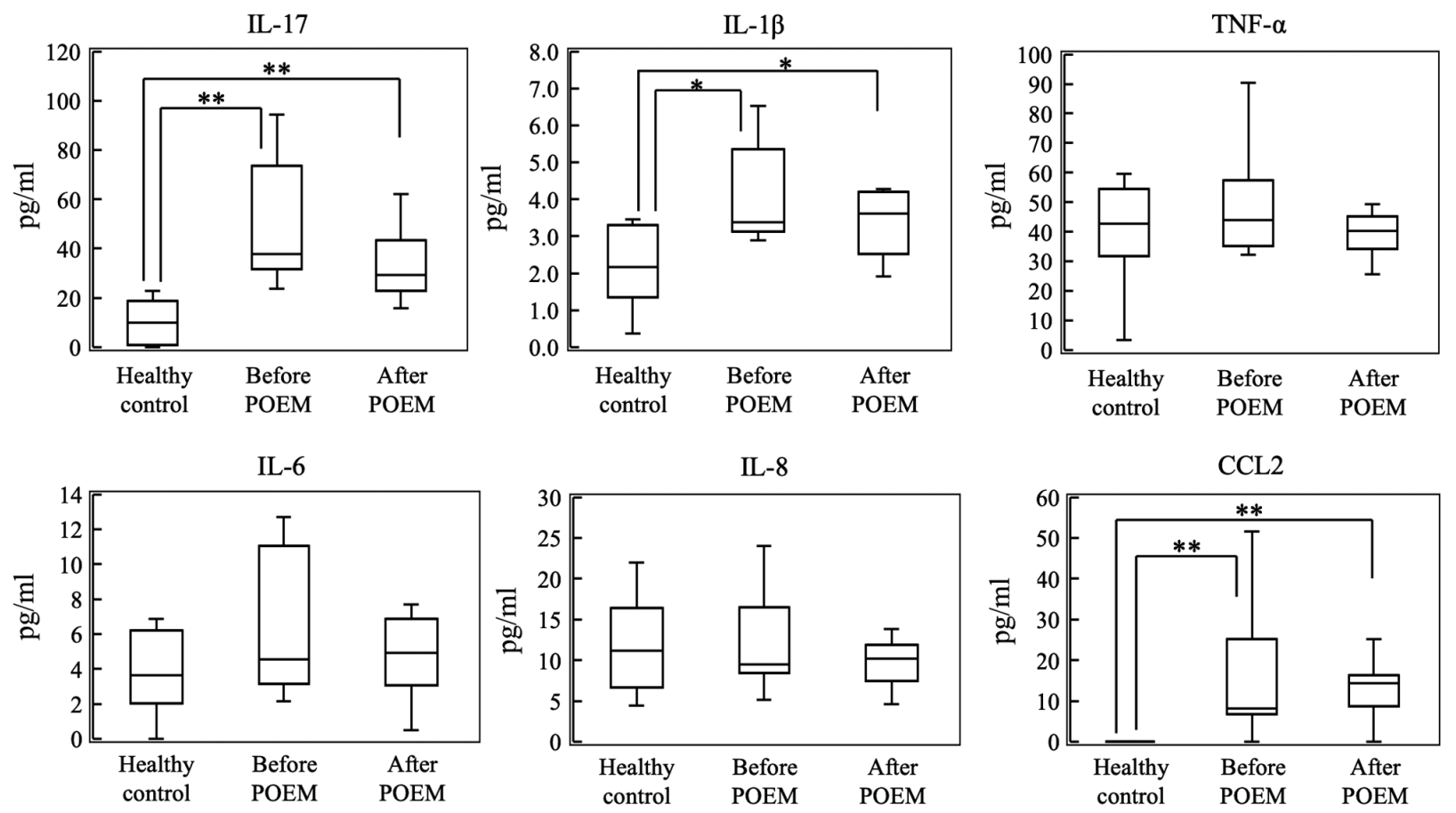

Figure 1. Plasma levels of IL-17, IL-1 $\beta$, TNF- $\alpha$, IL-6, IL- 8 and CCL2 in the control group, and before and after POEM in the patients with achalasia. "P $<0.05$, ${ }^{* *} \mathrm{P}<0.01$. POEM, peroral endoscopic myotomy; IL, interleukin; TNF- $\alpha$, tumor necrosis factor- $\alpha$; CCL, chemokine (C-C motif) ligand.

with grade I, 7 patients had grade II and 1 patient had grade III achalasia.

Cytokine analysis. The Bio-Plex Pro ${ }^{\mathrm{TM}}$ Human Cytokine 27-plex assay kit (cat. no. M500KCAF0Y) was purchased from Bio-Rad Laboratories, Inc. The collected plasma samples were diluted 4-fold with the sample diluent buffer. Antibody-bead conjugates were placed in the wells of a 96 well microplate and incubated first with the diluted plasma or the standard for $1 \mathrm{~h}$ at $20-25^{\circ} \mathrm{C}$ with constant shaking, followed by incubation with a biotin-labeled antibody for $30 \mathrm{~min}$ at $20-25^{\circ} \mathrm{C}$ and streptavidin-phycoerythrin conjugates for $10 \mathrm{~min}$ at $20-25^{\circ} \mathrm{C}$ (both after washing and shaking). The biotin-labeled antibody and streptavidin-phycoerythrin conjugates were part of the assay kit. After a further wash, the assay buffer was added to wells to re-suspend the beads, and fluorescence was measured using an automatic immunoassay analyzer (Bio-Plex ${ }^{\circledR} 200$ System; Bio-Rad Laboratories, Inc.). Finally, the cytokine concentration was calculated from the standard curve.

Statistical analysis. Differences were analyzed using a Mann-Whitney U test or a Dunn's test following a Kruskal-Wallis test. Statistical analysis was performed using StatFlex version 7 (Artec Co., Ltd.). A Shapiro-Wilk test using EZR version 1.54 (based on $\mathrm{R}$ version 4.1.0) was used to assess the distribution of the data. Data are presented as box plots, with the minimum, 25th percentile, median, 75 th percentile and maximum values forming the plots. $\mathrm{P}<0.05$ was considered to indicate a statistically significant difference.

\section{Results}

Patient characteristics. There was no significant differences in terms of age between the patients and controls. However, a significant difference in sex was observed in the expression of IL-7, IL-10, IL-12, IL-17, FGF2, CSF3, CCL4 and VEGF; expression levels of these cytokines were higher in females compared with males (Fig. S1A). Furthermore, serum IL-10 levels in patients undergoing endoscopic balloon dilation before POEM were higher than those in untreated patients (Fig. S1B). However, differences due to other clinical patient characteristics were not observed.

Cytokines are involved in the differentiation and maintenance of Th17 cells. As shown in Fig. 1, plasma levels of IL-17, IL-1 $\beta$ and CCL2 were significantly higher in patients with achalasia compared with the control subjects. However, plasma levels of TNF- $\alpha$, IL-6 and IL- 8 were not significantly increased in patients with achalasia when compared with those of the control subjects. Furthermore, there were no differences in cytokine levels in the plasma collected before and after POEM.

Th2-derived cytokines. As shown in Fig. 2, the plasma levels of IL-4 and IL-5 were significantly higher in the plasma of achalasia patients compared with the control subjects. However, plasma levels of IL-9 and IL-13 were not significantly increased in patients with achalasia when compared with those in the plasma of the control subjects. Furthermore, no differences in cytokine levels were detected in the plasma collected before and after POEM.

Cytokines are involved in the differentiation and maintenance of Thl cells. As shown in Fig. 3, plasma levels of IL-1ra, IL-7, IL-12, IFN- $\gamma$ and IL-2 were significantly higher in patients with achalasia compared with the control subjects. However, the plasma levels of CXCL10, IL-10 and IL-15 did not significantly increase in patients with achalasia when compared with 

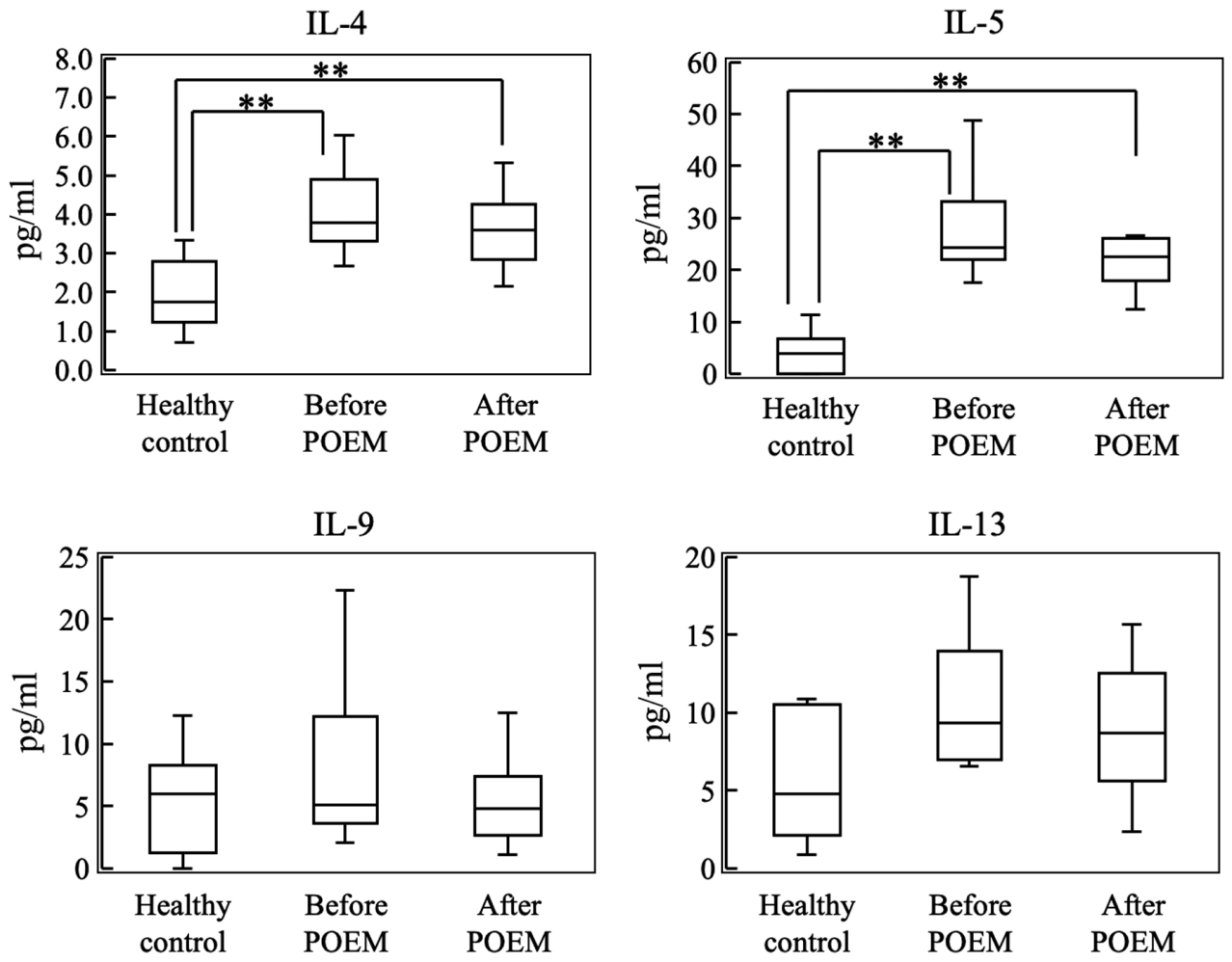

Figure 2. Plasma levels of IL-4, IL-5, IL-9 and IL-13 in the control group, and before and after POEM in the patients with achalasia. ${ }^{* *} \mathrm{P}<0.01$. POEM, peroral endoscopic myotomy; IL, interleukin.
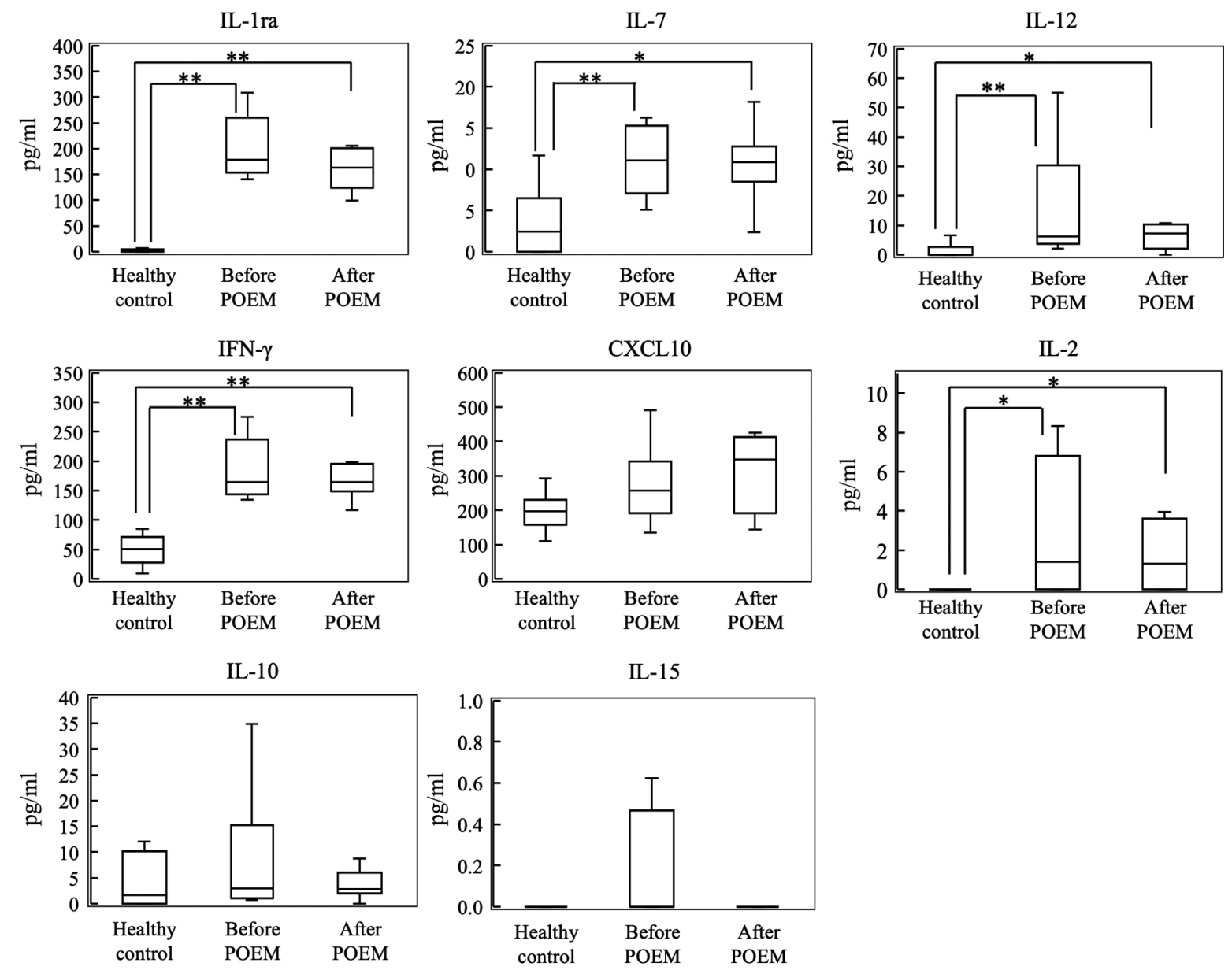

Figure 3. Plasma levels of IL-1ra, IL-7, IL-12, IFN- $\gamma$, CXCL10, IL-2, IL-10 and IL-15 in the control group, and before and after POEM in the patients with achalasia. ${ }^{*} \mathrm{P}<0.05,{ }^{* * *} \mathrm{P}<0.01$. POEM, peroral endoscopic myotomy; IL, interleukin; IFN- $\gamma$, interferon- $\gamma$. 

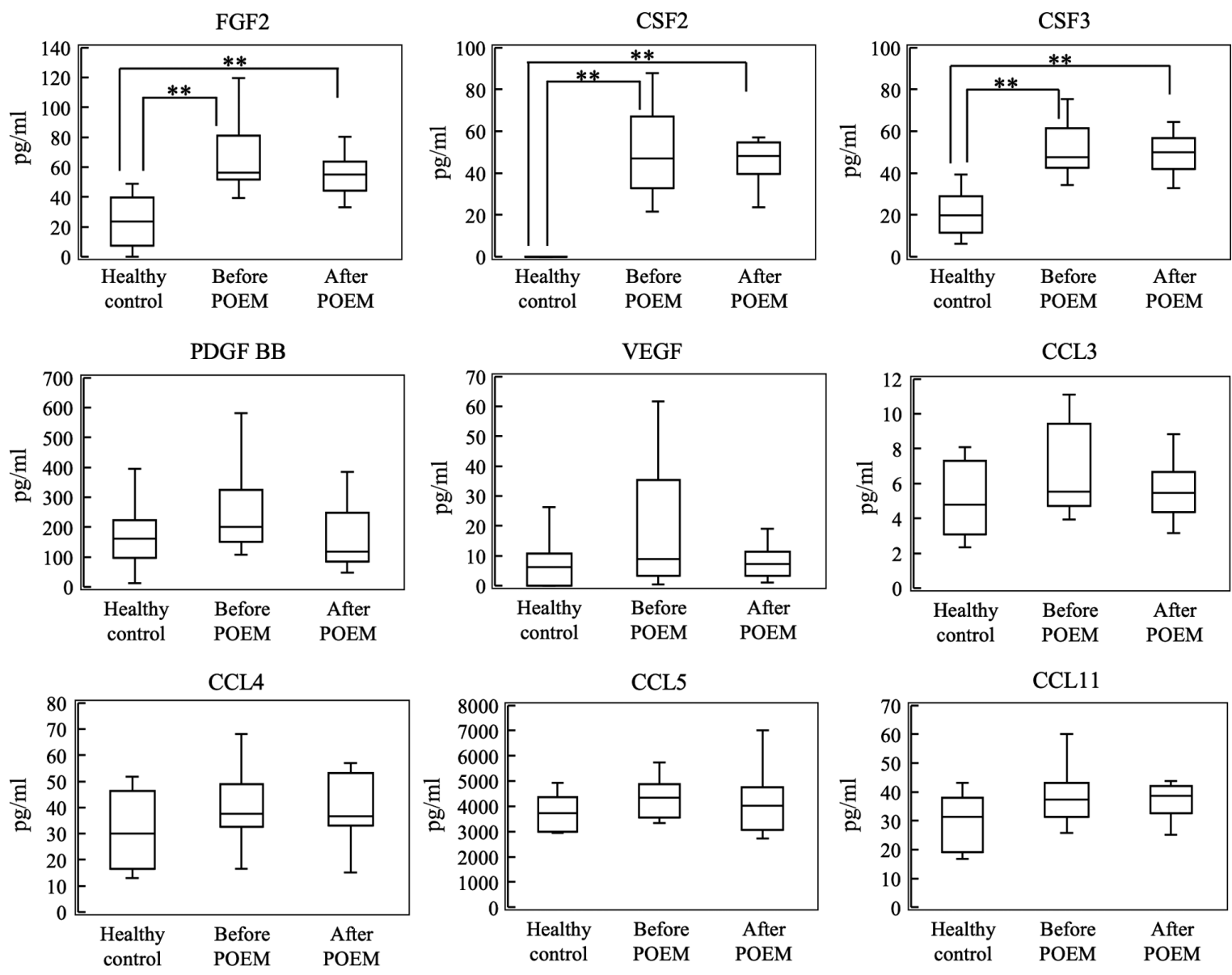

Figure 4. Plasma levels of FGF2, CSF2, CSF3, PDGF BB, VEGF, CCL3, CCL4, CCL5 and CCL11 in the control group, and before and after POEM in the patients with achalasia. "* $\mathrm{P}<0.01$. POEM, peroral endoscopic myotomy; IL, interleukin; FGF2, fibroblast growth factor 2; CSF, colony stimulating factor; PDGF, platelet-derived growth factor; VEGF, vascular endothelial growth factor; CCL, chemokine (C-C motif) ligand.

those the control subjects. Furthermore, there were no differences in cytokine levels in the plasma samples collected before and after POEM.

Growth factors and chemokines. As shown in Fig. 4, plasma levels of FGF2, CSF2 and CSF3 levels were significantly higher in patients with achalasia compared with the control subjects. However, plasma levels of PDGF-BB, VEGF, CCL3, CCL4, CCL5 and CCL11 were not significantly increased in patients with achalasia when compared with the control subjects. Furthermore, no differences in cytokine levels were detected in the plasma samples collected before and after POEM.

\section{Discussion}

The hypothesis developed in the present study regarding the mechanism of cytokine storm induction is shown in Fig. 5. IL-1 $\beta$ induced in LES stimulates the immune and inflammatory systems. IL-1 $\beta$ activates macrophages, polymorphonuclear leukocytes (PMNs) and T cells. These cells activate viral clearance and induce inflammation. Activated T cells, B cells and natural killer (NK) cells produce and release cytokines, which re-activate macrophages, PMNs and T cells.

The expression of IL-7, IL-10, IL-12, IL-17, FGF2, CSF3, CCL4 and VEGF is higher in females than in males.
Estrogen, a female hormone, inhibits the production of Th1 pro-inflammatory cytokines, such as IL-12, TNF- $\alpha$ and IFN- $\gamma$, and stimulates the production of Th2 anti-inflammatory cytokines, such as IL-10, IL-4 and TGF- $\beta$ (19). However, these previous results differ from the results in the present. Thus, there is a possibility of the influence of achalasia on cytokine levels.

IL-17 is an essential mediator of inflammatory autoimmune diseases. It promotes neutrophil recruitment and innate immune cell activation, enhances B cell function and induces inflammatory cytokines (IL-1 $\beta$ and TNF- $\alpha$ ). Under physiological and pathological conditions, IL-17 stimulates $\mathrm{T}$ cells and increases autoantibody production and inflammatory cytokines (TNF- $\alpha$, IL-1 $\beta$, IL-6, IL-8, IL-17 and IL- 22). Chemokines (CCL2, CCL7, CCL20, CXCL1 and CXCL5) induce neutrophil recruitment through chemokine regulation, activate innate immune cells, and enhance B cell function (20). Plasma levels of IL-17, IL-1 $\beta$ and CCL2 were significantly higher in patients with achalasia compared with the control subjects. These data were consistent with the higher tissue expression levels of IL-1 $\beta$ in patients with achalasia compared with the control subjects (21). These findings suggest that IL-17 induced the expression of Il-1 $\beta$ and CCL2, which is characteristic of the cytokine storm induced by COVID-19, in-turn increasing the expression of IL-1 $\beta$, IL-8, CCL2 and TNF- $\alpha$ (15-17). 


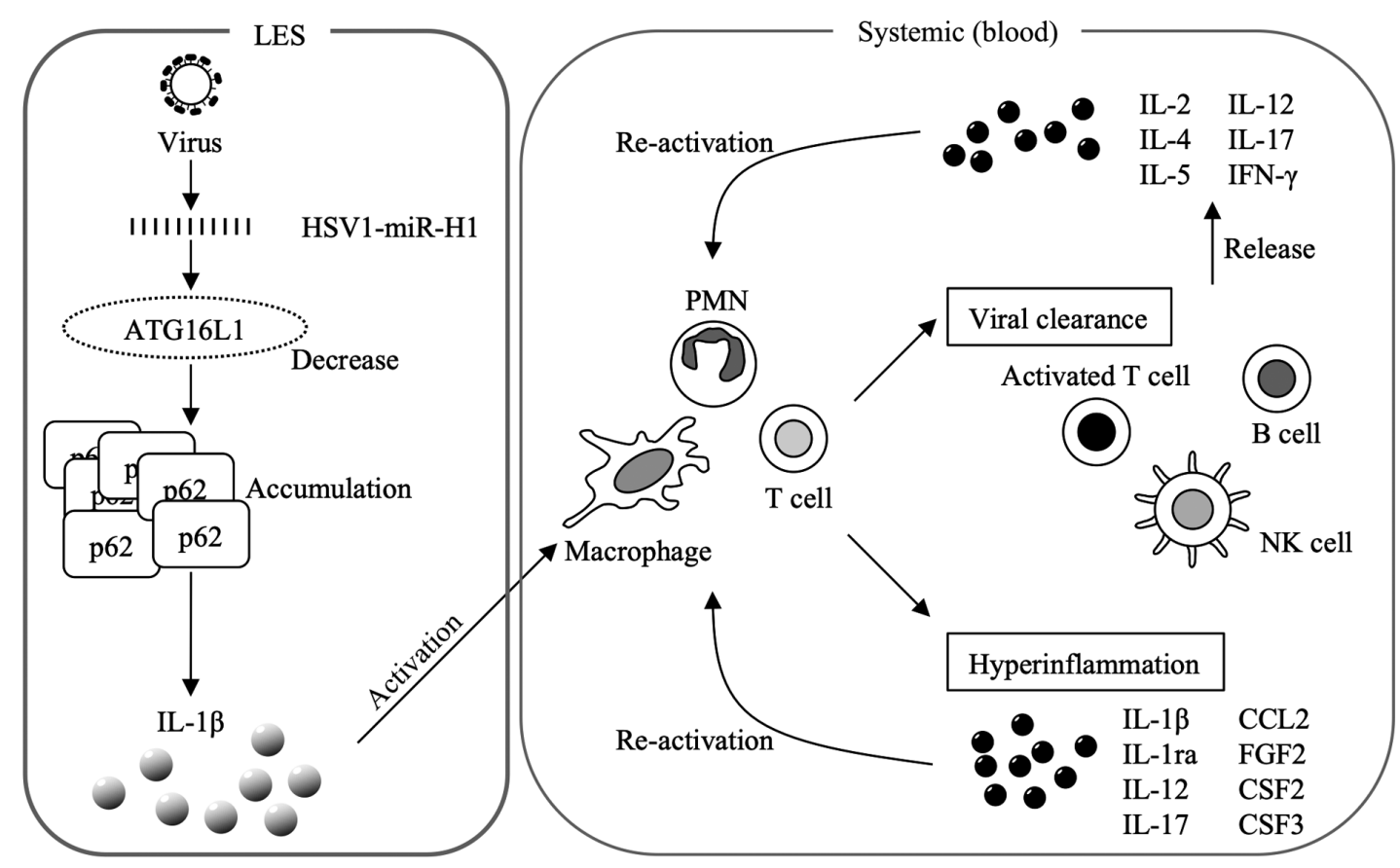

Figure 5. Mechanism of induction underlying the cytokine storm. IL-1 $\beta$ activates macrophages, PMNs and T cells. Macrophages, PMNs and T cells activate viral clearance and induce hyperinflammation. The activated T, B and NK cells produce cytokines. These released cytokines re-activate macrophages, PMNs and T cells. IL, interleukin; PMN, polymorphonuclear leukocytes; NK, natural killer; IFN- $\gamma$, interferon- $\gamma$; miR, microRNA; HSV herpes simplex virus; CCL, chemokine (C-C motif) ligand; FGF2, fibroblast growth factor 2; CSF, colony stimulating factor.

IL-4, which is synthesized primarily by Th2 cells, is an anti-inflammatory cytokine. It inhibits the synthesis of IL-17, IL- $1 \beta$, TNF- $\alpha$ and IL- 6 , and regulates B cell proliferation and differentiation. Furthermore, it is a potent inhibitor of apoptosis. IL-4 is a pro-fibrogenic cytokine $(22,23)$ that may also contribute to the fibrous outcome observed in the LES muscle of patients with achalasia.

In the present study, it was shown that IL-4 levels were higher in patients with achalasia compared with the control subjects. Interestingly, the levels of two conflicting cytokines were elevated, exhibiting a crucial feature of a cytokine storm $(17,24,25)$. TNF- $\alpha$, IL-6 and IL-8 levels were not significantly increased when compared with control plasma samples, which could be attributed to upregulation of IL-4. However, further research is required to confirm this relationship. Moreover, the IL-4-expressing $\mathrm{CD}^{+}{ }^{+} \mathrm{Th} 2$ subset is characterized by the production of IL-4, IL-5, IL-9 and IL-13, and serves a role in type 2 immunity to combat infectious diseases. These cells suppress autoimmune diseases mediated by Th1 cells (26). IL-5 levels were higher in patients with achalasia compared with the control subjects; the levels of IL-13, which exhibit an IL-4 like function, were also higher. However, IL-9 levels did not increase, dissimilar to that observed in the cytokine storm induced by COVID-19 (15-17). These data suggest the need to further investigate the cytokine storm in patients with achalasia.

The anti-inflammatory cytokine, IL-1ra, inhibits IL-1 $\beta$, regulating various IL-1-related immune responses and inflammatory responses, particularly during the acute phase of infection and inflammation (27-29). IL-7 is essential for $\mathrm{B}$ and $\mathrm{T}$ cell development and maintenance of naïve and memory T cells (30-32). IL-12 acts on T and NK cells, presents a broad array of biological functions and is essential for the differentiation of both Th1 and Th2 cells (33-36). Another critical cytokine, IFN- $\gamma$, released by Th1 cells, is also essential for regulating the Th2 response; it is implicated in regulating the immune response $(35,37,38)$. Specifically, this cytokine recruits leukocytes to infected tissues to potentiate beneficial inflammation and stimulate macrophages to engulf and kill bacteria (39-41). Moreover, IFN- $\gamma$ induces the production of several chemokines, such as CXCR3, CXCL9, CXCL10 and CXCL11 (20). IL-2 is a secreted cytokine produced by activated $\mathrm{CD}^{+}$and $\mathrm{CD}^{+}$lymphocytes, and is crucial for $\mathrm{T}$ cell and B cell lymphocyte proliferation (42-44). IL-1ra, IL-7, IL-12, IFN- $\gamma$ and IL-2 levels were significantly higher in the plasma of patients with achalasia compared with the control subjects. These data were consistent with the higher tissue expression levels of IL-2 detected in patients with achalasia compared with the control subjects (21). Additionally, CXCL10, IL-10 and IL-15 levels were higher in patients with achalasia compared with the control subjects. These data are characteristic of the cytokine storm induced by COVID-19, in which, increased levels of IL-1ra, IL-7, IFN- $\gamma$, CXCL10, IL-2 and IL-10 are observed (15-17). However, it is presumed that the significantly higher serum IL-10 levels in patients who underwent endoscopic balloon treatment are identical to those of IL-10, which serves an essential role in skin wound healing (45).

The plasma levels of FGF2, CSF2 and CSF3 were significantly higher in patients with achalasia compared with the control subjects. Additionally, PDGF-BB, VEGF, CCL3,CCL4, CCL5 and CCL11 levels were higher in patients with achalasia compared with the control subjects. As above, these data are characteristic of the cytokine storm induced by COVID-19, in which the levels of FGF2, CSF2, CSF3, PDGF-BB, VEGF, CCL3 and CCL4 levels are increased (15-17). 
IL-22 belongs to the IL-10 superfamily, and is involved in the innate immune response to intestinal epithelial and respiratory cell pathogens, tissue repair/regeneration processes and antibody production. Th22 and Th17 cells synthesize IL-22. Transforming growth factor (TGF)- $\beta 1$ regulates cell growth, proliferation, differentiation, inflammation, collagen synthesis and apoptosis. The number of IL- $22^{+}$and TGF- $\beta 1^{+}$cells observed in the myenteric plexus of esophageal biopsies are significantly higher in patients with achalasia than in control subjects $(5,13)$. Moreover, serum levels of IL-22, IL-17A and IFN- $\gamma$ were higher in 27 patients with achalasia compared with those in healthy volunteers (46). In the present study, IL-22 and TGF- $\beta$ levels were not evaluated, as these cytokines could not be detected using the ELISA kit employed. Therefore, IL-22 and TGF- $\beta$ levels in patients with achalasia remain to be investigated.

Taking plasma cytokine measurements before and after POEM is a novel approach not previously used in studies on achalasia, to the best of our knowledge. However, no significant differences in cytokine production before and after POEM were observed in the present study. Indeed, it is expected that POEM, which treats only part of the muscle, does not affect plasma cytokine levels. As POEM is a symptomatic treatment to improve food passage, cyclooxygenase- 2 inhibitors are required for preventative treatment and suppression of inflammation.

A limitation of the present study is that plasma biomarker levels may not correctly reflect tissue inflammation in the LES and esophageal mucosa. Furthermore, the sample size of patients with achalasia and the number of cytokines that can be detected with the ELISA kit employed may have limited the observed associations. In particular, the plasma mRNA or protein levels of ATG16L1 were not assessed as previously reported (14). However, the findings of this study may encourage further investigation with larger cohorts and a broader panel of biomarkers. Moreover, according to a previous study, TGF- $\beta 1$, TGF- $\beta 2$, TGF- $\beta 3$, IL-1ra, IL-17, IL-18, IFN- $\gamma$, MIG, PDGF-BB, CXCL10 (also known as IP-10) and stem cell growth factor-B levels are significantly higher in patients with achalasia compared with control subjects (47). TGF- $\beta 2$, IL-1ra, IL-2ra, IL-18, MIG, IFN- $\gamma$, SDF-1a, CCL11 (also known as eotaxin), PDGF-BB, CXCL10, CCL2 and TRAIL levels were significantly higher in type III achalasia compared with type I/II achalasia (47). It has been reported that IL-6 levels are significantly higher in patients with achalasia compared with patients with eosinophilic esophagitis (EoE), and they do not differ amongst the three achalasia subtypes (48). Another limitation of the present study is that no comparison was performed between achalasia subtypes or between achalasia and other benign esophageal diseases (especially EoE).

In conclusion, a cytokine storm can occur in patients with achalasia; this knowledge may assist in improving our understanding of this disease and in the development of a suitable treatment.

\section{Acknowledgements}

Not applicable.

\section{Funding}

No funding was received.

\section{Availability of data and materials}

The datasets used and/or analyzed during the present study are included in the published article.

\section{Authors' contributions}

TK and AY substantially contributed to the acquisition, analysis and interpretation of data, and drafted the manuscript. $\mathrm{KO}, \mathrm{HM}, \mathrm{NY}$ and YI substantially contributed to the acquisition, analysis, and interpretation of data. KN contributed to the conception and design of the study. HI made substantial contributions to the conception and design of the study, and to drafting of the manuscript. All authors have read and approved the final manuscript. TK and AY confirm the authenticity of all the raw data.

\section{Ethics approval and consent to participate}

The study protocol used in the present study followed the ethical guidelines of the Declaration of Helsinki and was approved by the Nagasaki University Ethics Committee (approval no. 13012899). Written informed consent was obtained from all patients for participation in the present study.

\section{Patient consent for publication}

Not applicable.

\section{Competing interests}

The authors declare that they have no competing interests.

\section{References}

1. Ikebuchi Y, Kanda T, Ikeda H, Yoshida A, Sakaguchi T, Urabe S, Minami H, Nakao K, Kuwamoto S, Inoue H, et al: Identification of human herpes virus 1 encoded microRNAs in biopsy samples of lower esophageal sphincter muscle during peroral endoscopic myotomy for esophageal achalasia. Dig Endosc 32: 136-142, 2020.

2. Kahrilas PJ and Boeckxstaens G: The spectrum of achalasia: Lessons from studies of pathophysiology and high-resolution manometry. Gastroenterology 145: 954-965, 2013.

3. Minami $\mathrm{H}$, Isomoto $\mathrm{H}$, Miuma $\mathrm{S}$, Kobayashi $\mathrm{Y}$, Yamaguch N, Urabe S, Matsushima K, Akazawa Y, Ohnita K, Takeshima F, et al: New endoscopic indicator of esophageal achalasia: 'Pinstripe pattern'. PLoS One 10: e0101833, 2015.

4. Ghoshal UC, Daschakraborty SB and Singh R: Pathogenesis of achalasia cardia. World J Gastroenterol 18: 3050-3057, 2012.

5. Furuzawa-Carballeda J, Torres-Landa S, Valdovinos MÁ, Coss-Adame E, Martín Del Campo LA and Torres-Villalobos G: New insights into the pathophysiology of achalasia and implications for future treatment. World J Gastroenterol 22: 7892-7907, 2016.

6. Inoue H, Shiwaku H, Iwakiri K, Onimaru M, Kobayashi Y, Minami H, Sato H, Kitano S, Iwakiri R, Omura N, et al: Clinical practice guidelines for peroral endoscopic myotomy. Dig Endosc 30: 563-579, 2018.

7. Isomoto H and Ikebuchi Y: Japanese guidelines for peroral endoscopic myotomy: 1st edition. Dig Endosc 31: 27-29, 2019.

8. Sato H, Inoue H, Ikeda H, Sato C, Santi EGR, Phalanusitthepha C, Aoyagi Y and Kudo SE: In vivo histopathological assessment of the muscularis propria in achalasia by using endocytoscopy (with video). Endosc Int Open 2: E178-E182, 2014.

9. Bredenoord AJ, Fox M, Kahrilas PJ, Pandolfino JE, Schwizer W and Smout AJ; International High Resolution Manometry Working Group: Chicago classification criteria of esophageal motility disorders defined in high resolution esophageal pressure topography. Neurogastroenterol Motil 24 (Suppl 1): 57-65, 2012. 
10. Kahrilas PJ, Bredenoord AJ, Fox M, Gyawali CP, Roman S, Smout AJ, Pandolfino JE, Bhatia S, Boeckxstaens G, Bor S, et al; International High Resolution Manometry Working Group: The Chicago Classification of esophageal motility disorders, v3.0. Neurogastroenterol Motil 27: 160-174, 2015.

11. Nakajima N, Sato H, Takahashi K, Hasegawa G, Mizuno K, Hashimoto S, Sato Y and Terai S: Muscle layer histopathology and manometry pattern of primary esophageal motility disorders including achalasia. Neurogastroenterol Motil 29: 1-8, 2017.

12. Pressman A and Behar J: Etiology and pathogenesis of idiopathic achalasia. J Clin Gastroenterol 51: 195-202, 2017.

13. Furuzawa-Carballeda J, Aguilar-León D, Gamboa-Domínguez A, Valdovinos MA, Nuñez-Álvarez C, Martín-del-Campo LA, Enríquez AB, Coss-Adame E, Svarch AE, Flores-Nájera A, et al: Achalasia - an autoimmune inflammatory disease: Across-sectional study. J Immunol Res 2015: 729217, 2015.

14. Kanda T, Yoshida A, Ikebuchi Y, Ikeda H, Sakaguchi T, Urabe S, Minami H, Nakao K, Inoue H and Isomoto H: Autophagy-related 16-like 1 is influenced by human herpes virus 1 -encoded microRNAs in biopsy samples from the lower esophageal sphincter muscle during per-oral endoscopic myotomy for esophageal achalasia. Biomed Rep 14: 7, 2021.

15. Nile SH, Nile A, Qiu J, Li L, Jia X and Kai G: COVID-19: Pathogenesis, cytokine storm and therapeutic potential of interferons. Cytokine Growth Factor Rev 53: 66-70, 2020.

16. Rothan HA and Byrareddy SN: The epidemiology and pathogenesis of coronavirus disease (COVID-19) outbreak. J Autoimmun 109: $102433,2020$.

17. Huang C, Wang Y, Li X, Ren L, Zhao J, Hu Y, Zhang L, Fan G, $\mathrm{Xu}$ J, Gu X, et al: Clinical features of patients infected with 2019 novel coronavirus in Wuhan, China. Lancet 395: 497-506, 2020.

18. Japan Esophageal Society: Descriptive rules for achalasia of the esophagus, June 2012: 4th Edition. Esophagus 14: 275-289, 2017.

19. Salem ML: Estrogen, a double-edged sword: Modulation of TH1and $\mathrm{TH} 2$-mediated inflammations by differential regulation of TH1/TH2 cytokine production. Curr Drug Targets Inflamm Allergy 3: 97-104, 2004.

20. Dardalhon V,Korn T, Kuchroo VK and Anderson AC: Role of Th1 and Th17 cells in organ-specific autoimmunity. J Autoimmun 31: 252-256, 2008

21. Facco M, Brun P, Baesso I, Costantini M, Rizzetto C, Berto A, Baldan N, Palù G, Semenzato G, Castagliuolo I, et al: T cells in the myenteric plexus of achalasia patients show a skewed TCR repertoire and react to HSV-1 antigens. Am J Gastroenterol 103: 1598-1609, 2008.

22. Huaux F, Liu T, McGarry B, Ullenbruch M and Phan SH: Dual roles of IL-4 in lung injury and fibrosis. J Immunol 170 2083-2092, 2003.

23. Nguyen JK, Austin E, Huang A, Mamalis A and Jagdeo J: The IL-4/IL-13 axis in skin fibrosis and scarring: Mechanistic concepts and therapeutic targets. Arch Dermatol Res 312: 81-92, 2020.

24. Fajgenbaum DC and June $\mathrm{CH}$ : Cytokine storm. N Engl J Med 383: 2255-2273, 2020

25. 25. Yiu HH, Graham AL and Stengel RF: Dynamics of a cytokine storm. PLoS One 7: e45027, 2012.

26. Wynn TA: Type 2 cytokines: Mechanisms and therapeutic strategies. Nat Rev Immunol 15: 271-282, 2015.

27. Dinarello CA: Overview of the IL-1 family in innate inflammation and acquired immunity. Immunol Rev 281: 8-27, 2018.

28. Zhang J-M and An J: Cytokines, inflammation and pain. Int Anesthesiol Clin 69: 482-489, 2009.

29. Martin P, Goldstein JD, Mermoud L, Diaz-Barreiro A and Palmer G: IL-1 family antagonists in mouse and human Skin inflammation. Front Immunol 12: 652846, 2021.
30. Fry TJ and Mackall CL: The many faces of IL-7: From lymphopoiesis to peripheral $\mathrm{T}$ cell maintenance. J Immunol 174: 6571-6576, 2005.

31. Surh CD and Sprent J: Homeostasis of naive and memory T cells. Immunity 29: 848-862, 2008

32. Chetoui N, Boisvert M, Gendron S and Aoudjit F: Interleukin-7 promotes the survival of human $\mathrm{CD}^{+}$effector/memory $\mathrm{T}$ cells by up-regulating Bcl-2 proteins and activating the JAK/STAT signalling pathway. Immunology 130: 418-426, 2010.

33. Vignali DA and Kuchroo VK: IL-12 family cytokines: Immunological playmakers. Nat Immunol 13: 722-728, 2012.

34. Lu X: Impact of IL-12 in Cancer. Curr Cancer Drug Targets 17: 682-697, 2017.

35. Zhang Y, Zhang Y, Gu W and Sun B: TH1/TH2 cell differentiation and molecular signals. Adv Exp Med Biol 841: 15-44, 2014.

36. Seder RA: The role of IL12 in the regulation of Th1 and Th2 differentiation. Res Immunol 146: 473-476, 1995.

37. Kaiko GE, Horvat JC, Beagley KW and Hansbro PM: Immunological decision-making: How does the immune system decide to mount a helper T-cell response? Immunology 123: 326-338, 2008.

38. Schoenborn JR and Wilson CB: Regulation of interferon-gamma during innate and adaptive immune responses. Adv Immunol 96: 41-101, 2007.

39. Chaplin DD: Overview of the immune response. J Allergy Clin Immunol 125 (Suppl 2): S3-S23, 2010.

40. Schroder K, Hertzog PJ, Ravasi T and Hume DA: Interferon- $\gamma$ : An overview of signals, mechanisms and functions. J Leukoc Biol 75: 163-189, 2004.

41. Bastos KR, Barboza R, Sardinha L, Russo M, Alvarez JM and Lima MR: Role of endogenous IFN- $\gamma$ in macrophage programming induced by IL-12 and IL-18. J Interferon Cytokine Res 27: 399-410, 2007.

42. Bachmann MF and Oxenius A: Interleukin 2: From immunostimulation to immunoregulation and back again. EMBO Rep 8: 1142-1148, 2007.

43. Ross SH and Cantrell DA: Signaling and function of interleukin-2 in T lymphocytes. Annu Rev Immunol 36: 411-433, 2018.

44. Lipsky PE, Hirohata S, Jelinek DF, McAnally L and Splawski JB: Regulation of human B lymphocyte responsiveness. Scand J Rheumatol Suppl 76 (Suppl 76): 229-235, 1988.

45. King A, Balaji S, Le LD, Crombleholme TM and Keswani SG Regenerative wound healing: The role of interleukin-10. Adv Wound Care (New Rochelle) 3: 315-323, 2014.

46. Furuzawa-Carballeda J, Coss-Adame E, Romero-Hernández F, Zúñiga J,Uribe-Uribe N, Aguilar-León D, Valdovinos MA,NúñezÁlvarez CA, Hernández-Ramírez DF, Olivares-Martínez E, et al: Esophagogastric junction outflow obstruction: Characterization of a new entity? Clinical, manometric, and neuroimmunological description. Neurogastroenterol Motil 32: e13867, 2020.

47. Chen WF, Liu ZQ, Pu ZN, Xu JQ, Yao L, Wu XY, Xu XY, Xu JX, Zhu Y, Wang Y, et al: Multiplex immunoassays reveal increased serum cytokines and chemokines associated with the subtypes of achalasia. Neurogastroenterol Motil 32: e13832, 2020.

48. Clayton S, Cauble E, Kumar A, Patil N, Ledford D, Kolliputi N, Lopes-Virella MF, Castell D and Richter J: Plasma levels of TNF- $\alpha$, IL-6, IFN- $\gamma$, IL-12, IL-17, IL-22, and IL-23 in achalasia, eosinophilic esophagitis (EoE), and gastroesophageal reflux disease (GERD). BMC Gastroenterol 19: 28, 2019.

This work is licensed under a Creative Commons Attribution-NonCommercial-NoDerivatives 4.0 International (CC BY-NC-ND 4.0) License. 